\title{
Teoria das relações interpessoais de Peplau: análise fundamentada em Barnaum*
}

\author{
PEPLAU'S THEORY OF INTERPERSONAL RELATIONS: AN ANALYSIS BASED OF BARNUM \\ TEORÍA DE LAS RELACIONES INTERPERSONALES DE PEPLAU: \\ ANÁLISIS FUNDAMENTADAEN BARNUM
}

\author{
Vitória de Cássia Félix de Almeida', Marcos Venícios de Oliveira Lopes², \\ Marta Maria Coelho Damasceno ${ }^{3}$
}

\footnotetext{
* Trabalho desenvolvido na Disciplina Análise Crítica das Teorias de Enfermagem do Programa de PósGraduação em Enfermagem da Universidade Federal do Ceará - UFC.

1 Enfermeira. Mestre em Enfermagem. Doutoranda em Enfermagem do Programa de Pós-Graduação em Enfermagem da UFC. Professora Adjunta do Departamento de Enfermagem da Universidade Regional do Cariri - URCA. Bolsista da FUNCAP. vitfelix@bol.com.br.

2 Enfermeiro. Doutor em Enfermagem. Professor Adjunto do Departamento de Enfermagem da UFC.

3 Enfermeira. Doutora em

Enfermagem, Docente do Programa de PósGraduação em Enfermagem da UFC.

Pesquisadora do CNPq.
}

\section{RESUMO}

$\mathrm{O}$ uso de teorias na Enfermagem reflete um movimento da profissão em busca da autonomia e da delimitação de suas ações. Tornase, portanto, de extrema relevância que as teorias possam ser analisadas quanto à sua aplicabilidade na prática. Objetivamos realizar um estudo analíticodescritivo da Teoria das Relações Interpessoais de Peplau a partir do modelo de análise proposto por Barbara Barnum. Dentre os componentes estruturais que podem ser analisados em uma teoria selecionamos o elemento "processo", método preconizado para o desenvolvimento das ações de enfermagem, submetendo-o ao critério de utilidade de Barnum. A avaliação revelou que os pressupostos teóricos de Peplau são operacionalizáveis e podem servir de base em quaisquer situações nas quais os enfermeiros possam comunicar-se e interagir com seus pacientes.

\section{DESCRITORES}

Teoria de enfermagem.

Relações interpessoais.

Modelos de enfermagem.

\begin{abstract}
The use of theories in Nursing reflects a movement in the profession towards the autonomy and delimitation of its actions. It is, therefore, extremely relevant that theories may be analyzed as for their applicability to practice. The object of this study is to make an analytical-descriptive study of Peplau's Theory of Interpersonal Relations in Nursing from the model of analysis proposed by Barbara Barnum. Among the structural components that may be analyzed in a theory was chosen the element "process", a method recommended for the development of nursing actions, which was submitted to Barnum's criteria of usefulness. The assessment showed that Peplau's theoretical presuppositions are operational and may serve as a basis in any situation in which nurses communicate and interact with his/her patients.
\end{abstract}

\section{KEY WORDS}

Nursing theory. Interpersonal relations. Models of nursing.

\section{RESUMEN}

El uso de teorías en la Enfermería refleja un movimiento de la profesión en busca de la autonomía y de la delimitación de sus acciones. Se torna, por tanto, de extrema relevancia que las teorías puedan ser analizadas en cuanto a su aplicabilidad en la práctica. Objetivamos realizar un estudio analítico-descriptivo de la Teoría de las Relaciones Interpersonales de Peplau a partir del modelo de análisis propuesto por Bárbara Barnum. De los componentes estructurales, que pueden ser analizados en una teoría, seleccionamos el elemento "proceso", método preconizado para el desarrollo de las acciones de enfermería, sometiéndolo al criterio de utilidad de Barnum. La evaluación reveló que los presupuestos teóricos de Peplau son operacionalizables y pueden servir de base en cualesquier situaciones en las cuales los enfermeros puedan comunicarse e interactuar con sus pacientes.

\section{DESCRIPTORES}

Teoria de enfermería. Relaciones interpersonales. Modelos de enfermería. 


\section{INTRODUÇÃO}

O uso de teorias na Enfermagem reflete um movimento da profissão em busca da autonomia e da delimitação de suas ações. Durante sua história, a Enfermagem esteve sempre dependente de outras ciências sem que houvesse um corpo de conhecimento próprio, o que fomentou o desejo nos enfermeiros de conhecer sua verdadeira natureza e construir sua identidade.

A busca dessa especificidade resultou na formalização de conceitos e teorias, os quais passaram a ser encarados como o instrumental adequado para direcionar a enfermagem na busca de seus limites de atuação em relação a outros profissionais $^{(1)}$.

Teorias podem ser definidas como um conjunto de proposições utilizadas para descrever, explicar e predizer parte de uma realidade ${ }^{(2)}$, consistindo, portanto, na organização de algum fenômeno por meio da qual evidenciam-se os componentes e as características que lhes dão identidade ${ }^{(3)}$.

Nesse sentido, as teorias têm sido um passo fundamental em direção à compreensão da Enfermagem como práxis, entendida esta como ação aprofundada pela reflexão, carregada de sentido, projetada, consciente e transformadora da natureza, do homem e da sociedade ${ }^{(4)}$.

Apesar de sua importância, tem havido, por parte dos enfermeiros, questionamentos quanto à aplicabilidade das teorias na prática. Freqüentemente, ouvimos referências às dificuldades de operacionalização dessas no âmbito de sua atuação profissional.

Na prática docente, temos percebido que as dúvidas em relação à possibilidade de aplicar teorias numa situação real de cuidado surgem ainda no processo de formação dos alunos. No momento em que as teorias de enfermagem lhes são apresentadas, não raro os estudantes mencionam o fato de que o conhecimento é restrito ao ambiente acadêmico e que nos serviços de saúde dificilmente são aplicadas.

Por sua vez, uma estudiosa do assunto comenta que, em se tratando de modelos de assistência de enfermagem, há limites estruturais para a sua implantação nas instituições de saúde, assim como há limites profissionais para o ensino e aplicação das teorias, visto que não temos, nas escolas, nem recursos nem motivação para a sua utilização ${ }^{(4)}$.

Enquanto isso, é preciso considerar que a prática da enfermagem não abrange somente o fazer técnico mas também a origem e conseqüência desse fazer e, assim sendo, as teorias podem ser usadas pelos profissionais para orientar e melhorar a sua prática ${ }^{(5)}$.

Diante da problemática em torno da utilização das teorias de enfermagem, torna-se, pois, de extrema relevância que elas sejam analisadas quanto à sua utilidade, entendendo que, sem a existência concreta de uma relação entre teoria e prática, as teorias tendem a transformar-se em mera abstração intelectual.

Com a finalidade de possibilitar uma análise crítica acerca das várias teorias de enfermagem e sua adequação às diversas facetas do trabalho dos enfermeiros têm sido desenvolvidos modelos de análise que auxiliam o emprego de determinada teoria a uma situação específica ${ }^{(3,6)}$ quer na assistência, no ensino ou na pesquisa.

Uma das teorias considerada como marco teórico de referência para a prática da enfermagem e, sobretudo, para a enfermagem psiquiátrica é a Teoria das Relações Interpessoais desenvolvida por Hildegard E. Peplau, em 1952. A teorista visualizou o fenômeno de enfermagem como um processo interpessoal cujo foco principal está centralizado na enfermeira e no paciente e, em sua teoria, pretende identificar conceitos e princípios que dêem suporte às relações interpessoais que se processam na prática da enfermagem de modo que as situações de cuidado possam ser transformadas em experiências de aprendizagem e crescimento $\operatorname{pessoal}^{(7)}$.

Neste trabalho, propusemo-nos a analisar a utilidade da teoria proposta para o desenvolvimento das ações de enfermagem.

\section{AS BASES DA ANÁLISE DA TEORIA DE PEPLAU}

Para a consecução do objetivo proposto realizamos um estudo de caráter analítico e descritivo da Teoria das Relações Interpessoais.

Dentre os diferentes métodos e critérios elaborados por críticos de teorias de enfermagem, optamos pelo referencial de análise de Bárbara Barnum $^{(3)}$ que sugere inicialmente uma avaliação abrangente da teoria. Esta etapa da análise envolve: identificar os elementos principais da teoria; classificar a teoria em descritiva ou explicativa; determinar se a teoria descreve a enfermagem como é ou como deve ser e se ela diferencia a enfermagem de outras profissões ou ações de cuidado; identificar se o foco da teoria está centrado na ação
Teoria das Relações Interpessoais de

Peplau: análise fundamentada em Barnum

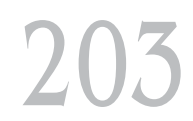

Rev Esc Enferm USP 2005; 39(2):202-10. 
Vitória de Cássia F. Almeida Marcos V. de O. Lopes Marta Maria C. Damasceno de enfermagem, no paciente ou no relacionamento enfermeiro-paciente; e, verificar se a teórica fornece alguma definição inconsistente com o restante da teoria.

Em seguida, a autora menciona que, ao analisar uma teoria de enfermagem, deve-se examinar seus componentes estruturais, a saber: contexto, conteúdo, processo e objetivo. O contexto refere-se ao ambiente no qual a ação de enfermagem acontece. O conteúdo envolve os aspectos que constituem a teoria e, com freqüência, é formado por categorias que explicam as ações de enfermagem. O processo é o método ou o conjunto de ações requeridas para implementar a teoria que podem ser executados pelo enfermeiro ou pelo paciente. O objetivo é a meta esperada pela aplicação da teoria.

Uma vez que sua estrutura e seus diversos componentes sejam analisados e classificados resta a tarefa de julgá-la ${ }^{(3)}$. Para executar este último passo da avaliação propõe a crítica interna e a crítica externa da teoria.

A crítica interna, de acordo com a autora, identifica como os diversos componentes estão interrelacionados e verifica a existência ou não de relações lógicas entre esses elementos. A construção interna da teoria é avaliada mediante o estudo dos critérios: clareza, consistência, adequação, desenvolvimento lógico e nível de desenvolvimento da teoria.

A crítica externa, por sua vez, reflete a forma como a teoria se relaciona com o mundo e com a enfermagem. Diferente da crítica interna, a crítica externa é altamente dependente das preferências e da percepção do leitor sobre o mundo. Os critérios usados para avaliar a crítica externa são: convergência com a realidade, utilidade, significância, discriminação (capacidade de diferenciar a enfermagem), alcance e complexidade da teoria.

Para a operacionalização do estudo da Teoria das Relações Interpessoais, no presente trabalho, focalizamos, dentre os elementos estruturais apresentados por Barnum, o processo na referida teoria. Submetemos o elemento processo à crítica externa, utilizando-nos para este fim do critério da utilidade.

A escolha do processo como foco para essa análise esteve associada ao fato de considerarmos que é nesse elemento que se encontra delineada a forma como o profissional deve conduzir suas ações em consonância com os pressupostos do teórico, não como um conjunto de regras, mas como um caminho para direcionar as ações de enfermagem com base numa análise crítica dos problemas identificados.

A idéia de analisar a utilidade do processo ocorreu por entendermos que é na forma como a teoria pode ser empregada que reside a essência da relação teoria-prática.

\section{HILDEGARD PEPLAU: ASPECTOS BIOGRÁFICOS}

Com a finalidade de contextualizar o trabalho de Peplau, cumpre destacar algumas passagens de sua biografia pessoal e profissional.

Hildegard Elizabeth Peplau nasceu em $1^{\circ}$ de setembro de 1909 em Reading, na Pensilvânia, sendo a segunda de seis filhos do casal Gustav e Ottylie Peplau. Na infância, presenciou a epidemia de gripe ocorrida em 1918, fato que influenciou sobremaneira em sua compreensão sobre o impacto da enfermidade e da morte para as famílias ${ }^{(8-9)}$.

Sua carreira na enfermagem teve início em 1931 com seus estudos em um programa de enfermagem em Pottstown, Pensilvânia. O trabalho em um acampamento de verão da "New York University" a levaria a exercer atividades como enfermeira no "Bennington College" onde graduou-se em Psicologia Interpessoal, em 1943. Em Bennington, participou de um estudo experimental com Erich From e Frida From-Reichmann, no "Chestnut Lodge" (uma instituição psiquiátrica privada). Ali estudou com Harry Stack Sullivan, eminente psiquiatra da época, e começou a dedicar sua vida a entender e a desenvolver a teoria interpessoal de Sullivan com a finalidade de aplicála à prática de enfermagem ${ }^{(8-10)}$.

Entre os anos de 1943 e 1945 compôs o grupo de enfermeiras do Exército dos Estados Unidos, trabalhando a maior parte desse tempo na Escola Militar de Neuropsiquiatria da Inglaterra, onde teve a oportunidade de conhecer os psiquiatras mais importantes do mundo. Obteve seus títulos de Mestre e Doutora no "Teachers College" da Universidade de Columbia, onde foi instrutora e diretora do programa avançado de enfermagem psiquiátrica de 1947 a 1953 - período em que formulou sua teoria. No ano de 1948 concluiu o livro "Interpersonal Relations in Nursing", o qual só foi publicado quatro anos mais tarde, por ser considerado muito revolucionário para a época que uma enfermeira publicasse um livro sem que houvesse pelo menos um médico com co-autor ${ }^{(8-9)}$. 
Também obteve formação em psicanálise pelo Instituto William Alanson White de Nova York.

No início dos anos cinqüenta, ministrou aulas de enfermagem psiquiátrica no "Teachers College" nas quais enfatizava a necessidade da experiência clínica com os pacientes psiquiátricos. Tornou obrigatório para as enfermeiras a entrevista com os pacientes, o registro das entrevistas realizadas e o estudo acerca dos padrões de interação. Com base nessas notas e na sua experiência pôde formular as definições de ansiedade, conflito e frustração presentes em sua teoria ${ }^{(9)}$. De 1954 a 1974 trabalhou como professora da Faculdade de Enfermagem de Rutgers e ali criou o primeiro programa de pós-graduação em enfermagem psiquiátrica.

Lutou de forma vigorosa para que as enfermeiras tivessem maiores oportunidades de formação e, assim, pudessem dar um verdadeiro cuidado terapêutico aos pacientes e não apenas serem guardiãs destes - papel que prevalecia à época nos hospitais psiquiátricos ${ }^{(8)}$.

Exerceu atividades como consultora da Organização Mundial de Saúde e como professora visitante em universidades da África, América Latina, Europa e Estados Unidos. Foi a única enfermeira a exercer os cargos de diretora executiva e presidenta da Associação de Enfermeiras Americanas (ANA). Também trabalhou junto ao Conselho Internacional de Enfermagem (CIE) por dois períodos ${ }^{(8-10)}$.

Faleceu em 17 de março de 1999, aos 89 anos, em sua casa em Sherman Oaks, Califórnia, após uma trajetória que influenciou profundamente a enfermagem a ponto de ela ser considerada a "enfermeira do século" e destacada, na área da psiquiatria, como "a mãe da enfermagem psiquiátrica". A partir do seu trabalho, o processo interperssoal passou a fazer parte de forma consciente e efetiva do ensino e da prática da enfermagem. Por isso, considera-se que a vida e o trabalho de Peplau produziram as maiores mudanças na prática de enfermagem depois de Florence Nigthingale ${ }^{(8)}$, tornando-a digna de várias honrarias ao longo de sua vida.

\section{TEORIA DAS RELAÇÕES INTERPESSOAIS DE PEPLAU: ABORDAGEM GERAL E UTILIDADE PARAA PRÁTICA DA ENFERMAGEM}

Com a apresentação de seu livro "Interpersonal Relations in Nursing: a conceptual frame of reference for psychodinamic nursing", em 1952, Hildegard Peplau introduziu um novo paradigma para a enfermagem centrado nas rela- ções interpessoais que se processam entre a enfermeira e o paciente.

Como em geral acontece com os escritores, foi fortemente influenciada pelas questões debatidas em sua época e, como ela própria reconhece no prefácio de sua obra, o que escreveu reflete, em alguma medida, as tendências dominantes e os problemas dos quais a enfermagem se ocupava no início dos anos 50 do século $\mathrm{XX}^{(7)}$.

Uma de tais questões referia-se à compreensão do que seria a enfermagem e em que consistiria a sua prática. Em resposta a esse questionamento central, a autora vislumbrou a enfermagem como um processo interpessoal por meio do qual, enfermeira e paciente podem obter crescimento e desenvolvimento pessoais ${ }^{(7)}$.

Obviamente, os elementos fundamentais da prática da enfermagem são o paciente, a enfermeira e os acontecimentos que envolvem ambos durante uma situação de cuidado. Eis, portanto, a importância fundamental de Peplau ao tentar "profissionalizar" o que a enfermagem, de certa forma, já realiza quando interage com o paciente, embora o faça, na grande maioria das vezes, de forma intuitiva $^{(9,11)}$.

De modo geral, as teóricas de enfermagem têm utilizado teorias lançadas fora do âmbito da enfermagem como base de sustentação para o desenvolvimento de suas próprias teorias. Entre as que foram elaboradas fora da enfermagem e que têm sido aplicadas a esse campo a fim de oferecer explicações para as relações entre homem, ambiente, saúde e enfermagem e guiar o processo de enfermagem, estão: a teoria de sistemas, da tensão e adaptação, do crescimento e desenvolvimento e do ritmo.

No que tange à Teoria das Relações Interpessoais de Peplau, pode-se dizer que seus fundamentos são as do crescimento e desenvolvimento, como os estudos de Erick Fromm e, sobretudo, a Teoria Interpessoal de Harry Stack Sullivan ${ }^{(10)}$.

De forma geral, essas teorias adotam como pressuposto básico que o crescimento e o desenvolvimento humanos ocorrem de forma gradual até a realização do seu potencial máximo. O crescimento é entendido como um aumento relacionado ao tamanho e formas físicas, ordenado e com tendências regulares em seu direcionamento, mas que acontece para cada pessoa em um padrão único influenciado por fatores intrínsecos e extrínsecos. $\mathrm{O}$ desenvolvimento, por outro lado, refere-se a mudanças funcionais no indivíduo, mais de caráter qualitativo, e que também recebem influências internas e externas ${ }^{(12)}$.
Teoria das Relações Interpessoais de

Peplau: análise fundamentada em Barnum 
Vitória de Cássia F. Almeida Marcos V. de O. Lopes Marta Maria C. Damasceno
A teoria de Sullivan, particularmente, baseiase na crença de que o comportamento e a personalidade dos indivíduos desenvolvem-se a partir das relações com pessoas consideradas importantes para eles. Embora, as etapas do desenvolvimento possam ser de caráter universal, não existem limites definidos para cada uma delas, as quais recebem grande influência das diferenças culturais. Para Sullivan, em cada fase, a satisfação e a segurança derivam do atendimento das necessidades do indivíduo e dos julgamentos de valores feitos por pessoas que tenham importância para esse indivíduo ${ }^{(12)}$.

Com base nessas proposições, Peplau traz em sua teoria a noção de "crescimento pessoal" que é compartilhado pela enfermeira e pelo paciente a partir do relacionamento interpessoal desenvolvido no processo de cuidar. A autora usou o termo "enfermagem psicodinâmica" para descrever o relacionamento dinâmico entre enfermeira e paciente. Em seu entendimento, a enfermagem psico-dinâmica envolve reconhecer, esclarecer e construir uma compreensão acerca do que acontece quando a enfermeira se relaciona de forma útil com o paciente ${ }^{(9)}$.

As etapas da enfermagem psicodinâmica desenvolvem-se tendo como base dois pressupostos fundamentais, a saber:

1. A postura adotada pela enfermeira interfere diretamente no que o paciente vai aprender durante o processo de cuidado ao longo de sua experiência como doente.

2. O auxílio ao desenvolvimento da perso-nalidade e ao amadurecimento é uma função da enfermagem que exige o uso de princípios e métodos que facilitem e orientem o processo de solução dos problemas ou dificuldades interpessoais cotidia$\operatorname{nos}^{(9)}$.

Peplau considera que na medida em que cada enfermeira compreenda sua própria função tanto mais ela compreenderá a situação do paciente e a forma como esse a concebe ${ }^{(9)}$.

A primeira parte da teoria oferece ao leitor alguns elementos fundamentais para prepará-lo a compreender as "influências, tarefas e métodos" que farão parte da relação entre enfermeira e paciente.

A autora afirma inicialmente que, uma vez que pretende fornecer um marco conceitual para a enfermagem psicodinâmica, cumpre esclarecer sua concepção de enfermagem ${ }^{(7)}$.
Na acepção apresentada em sua obra, a enfermagem é vista primariamente como um processo, considerado com base em suas fases e nos diferentes papéis que a enfermeira pode assumir $^{(7)}$. Ao assim dizer, a autora entende que a natureza da enfermagem sistematizada e dirigida a uma meta exige certas fases, ações, operações e realizações que se produzem entre o indivíduo que pratica a enfermagem e a pessoa $\operatorname{assistida~}^{(7)}$.

É necessário ressaltar que o processo vai muito além das técnicas de enfermagem, que poderão ser usadas ou não para resolver o problema do paciente, mas que por si só não o levam a amadurecer.

A enfermagem, na percepção da teórica, é uma relação humana entre uma pessoa que está enferma ou necessitada de serviços de saúde e uma enfermeira com uma formação especializada para reconhecer e responder a necessidade de $\operatorname{ajuda}^{(7)}$.

Mesmo enfatizando na sua teoria os aspectos psicológicos da prática da enfermagem, a autora reconhece que o cuidado físico do corpo de outro ser humano é fundamental, pois proporciona um tipo de 'intimidade interpessoal', uma proximidade de tal forma, que com muita freqüência induz a mente do paciente a realizar conexões entre as circunstâncias presentes e suas experiências anteriores que, de certo modo, são similares $^{(9)}$.

Defende a idéia do que poderíamos chamar de "enfermeira psicóloga". Como ela adverte, em sua teoria não se sugere que a enfermeira deva ser 'onipotente' e, em conseqüência, capaz de conseguir mudanças psicológicas nos pacientes em alguns minutos de interação enfermeira-paciente. O que se sugere, não é uma mudança de personalidade instantânea, e sim a utilização das oportunidades disponíveis por meio da aplicação da teoria e técnicas conhecidas das relações interpessoais $^{(9)}$.

O objetivo da assistência de enfermagem é ajudar os indivíduos e a comunidade a produzir mudanças que influenciem de forma positiva em suas vidas ${ }^{(9)}$. Nesse respeito, vale mencionar que as metas a serem atingidas deverão ser estabelecidas pelo enfermeiro e pelo paciente, pois caso os objetivos de ambos sejam desarmônicos, os resultados também o serão ${ }^{(2)}$. Ao incluir nos objetivos as mudanças em âmbito comunitário, Peplau evidencia que reconhece o papel da família, da sociedade, da cultura e do ambiente nas mudanças, mesmo que seja o ambiente hospita- 
lar o contexto predominante na teoria. Também aponta que um dos papéis que a enfermeira pode desenvolver é o de fazer com que os cuidados de saúde possam ser conduzidos do hospital para a comunidade $^{(2)}$.

Compreendemos esse objetivo delineado pela teórica quando analisamos as circunstâncias históricas nas quais a teoria encontra-se inserida. Nos anos 40 do século XX, as referências da enfermagem à pessoa como um todo foram o resultado da adição dos estudos psicossociais aos currículos, suplementando a visão exclusiva de homem biológico que dominara a educação de enfermagem até então. A mudança de foco nos anos 40 conduziu, na década seguinte, a uma aproximação holística do paciente, e a uma atuação da enfermagem voltada para atendê-lo em suas necessidades ${ }^{(2)}$. Com essa mudança, a ênfase no processo interpessoal como base para a intervenção de enfermagem emergiu e é nesse contexto que Hildegard Peplau desenvolve sua teoria.

Em relação ao processo de atuação da enfermagem, cumpre afirmar que esse representa a parte dinâmica da teoria. O processo ou processos de uma teoria implicam nas atividades, quer sejam de ordem afetiva, intelectual ou comporta-mental, requeridas para implementar uma teoria. Cumpre ainda ressaltar que diferentes problemas requerem diferentes métodos. Para algumas teóricas, o processo é reduzido a uma simples atividade. Para outras, numerosas ações estão envolvidas na execução do processo $^{(3)}$.

Em sua teoria, Peplau opta por descrever o processo de relação interpessoal da enfermagem em quatro fases: orientação, identificação, exploração e resolução. Essas etapas estão superpostas e devem ser consideradas de forma relacionada. $\mathrm{Na}$ fase de orientação, o paciente apresenta uma necessidade e solicita ajuda profissional. A enfermeira, inicialmente, identifica as necessidades do paciente, o qual, durante a interação, fornece muitas pistas a respeito de como visualiza a dificuldade que está experimentando e oferece à enfermeira a oportunidade de reconhecer suas carências de informação e compreensão acerca do problema. Diante das necessidades identificadas, a enfermeira, em colaboração com outros componentes da equipe de saúde, orienta o paciente acerca do problema e de suas implicações. A tensão e a ansiedade apresentadas por esse paciente em decorrência de suas necessidades devem ser levadas em consideração na fase de orientação, pois, caso contrário, não haverá êxito em tentar relacionar a sua experiência atual com as anteriores ${ }^{(7)}$.
O ambiente hospitalar é propício para a etapa de orientação, considerando que as limitações de espaço e liberdade de movimentos impulsionam o paciente ao seu próprio mundo imaginário e podem suscitar a oportunidade para que, com a ajuda do profissional, possa esclarecer e explicar o que acontece a sua volta ${ }^{(7)}$. No momento da hospitalização, os sentidos do paciente estão bastante aguçados e ele passa a observar detalhes cada vez menores $^{(7)}$, o que destaca a importância de, na fase de orientação, estar atento a qualquer necessidade do paciente mesmo que pareça irrelevante ou de menor importância.

Sobre esse último aspecto, a teórica reconhece que a celeridade, qualidade tão valorizada nas enfermeiras, na verdade não estimula a atitude investigativa diante do paciente. Em sua opinião toda enfermeira deveria, sempre que possível, "buscar uma cadeira, sentar com os pacientes e dizer: 'fale-me de você". O que ocorre muitas vezes, entretanto, é que traduzimos nosso contato com os pacientes como algo simples demais e os acontecimentos interpessoais importantes passam desper$\operatorname{cebidos}^{(9)}$. Como explica, não raramente achamos que nossos pacientes são apenas nosso "público" e deixamos de percebê-los como figuras essenciais, esquecendo-nos de suas reais necessidades $^{(9)}$.

À medida que a relação avança, passa-se à fase de identificação, na qual o paciente começa a responder seletivamente às pessoas que lhe oferecem a ajuda de que necessita ${ }^{(7)}$. Nessa fase, a enfermeira, no desempenho das ações de cuidado, pode levar o paciente a identificá-la como uma figura familiar ou culturalmente importante em suas lembranças. O paciente poderá responder de três formas: desenvolvendo ações de caráter participativo e interdependente com a enfermeira; isolando-se e assumindo uma atitude de independência em relação à enfermeira ou adotando uma postura de desamparo e dependência em relação a essa profissional $^{(9)}$.

Comenta que alguns pacientes se identificam tão facilmente com a enfermeira que esperam que ela atenda a todos os seus desejos, desconsiderando o fato de que, o relacionamento interpessoal pressupõe que haja uma interação entre ambos.

$\mathrm{Na}$ etapa de identificação os esforços da enfermeira devem direcionar-se para o auxílio do paciente na consecução de uma aprendizagem construtiva, a qual ocorre quando ele pode centrar-se nos elementos essenciais da situação, mediante seus próprios esforços, e quando pode desenvolver respostas independentemente da enfermeira ${ }^{(7)}$.
Teoria das Relações Interpessoais de

Peplau: análise fundamentada em Barnum

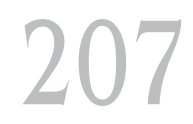

Rev Esc Enferm USP 2005; 39(2):202-10. 
Vitória de Cássia F. Almeida Marcos V. de O. Lopes Marta Maria C. Damasceno
A terceira fase do processo refere-se à exploração ao máximo da relação para a obtenção dos melhores benefícios possíveis. O paciente faz pleno uso dos serviços que lhe são oferecidos, entretanto, quando se inicia a recuperação, pode experimentar conflitos entre o seu estado de dependência e independência, a um só tempo. A atuação da enfermeira é continuar a promover a satisfação do paciente em relação às suas demandas à medida que elas surgem e, conforme avança a convalescência, deverão ser estabelecidas novas metas - como voltar para casa e ao trabalho - no intuito de diminuir a identificação do paciente com a pessoa que the prestou ajuda ${ }^{(7)}$.

A última fase denominada de "resolução" é caracterizada mais como um fenômeno psicológico em que o paciente abandona os laços adquiridos e prepara-se para retornar para casa. O ideal seria que essa fase coincidisse com a resolução de seu problema clínico, o que em muitos casos não acontece, pois o paciente mesmo recuperado não apresenta o desejo real de concluir a enfermidade ${ }^{(7)}$.

Para que a resolução aconteça de forma bem sucedida, há a necessidade da liberação gradual da identificação com as pessoas que prestaram ajuda e da criação e fortalecimento da capacidade de atuar por si mesmo ${ }^{(7)}$.

O paciente consegue lograr êxito nessa etapa quando as etapas anteriores foram amplamente satisfeitas e ocorreu um encadeamento adequado entre elas.

Durante todas as fases do processo interpessoal, indica que a enfermeira pode assumir diferentes papéis. Como "pessoa estranha" a enfermeira estabelece com o paciente uma interação baseada no respeito e no interesse, na qual o visualiza como uma pessoa emocionalmente capaz e busca utilizar expressões que promovam maior conforto psicológico. Outro papel é o de "pessoa recurso", o qual implica que a enfermeira deve fornecer reposta às perguntas dos pacientes, sobretudo às questões que envolvem sentimentos e que estão associadas aos maiores problemas enfrentados por eles. Também pode atuar como "educadora" e "líder", auxiliando o processo de aprendizagem do paciente à medida que promove a participação ativa do mesmo em suas experiências. Outros papéis que as enfermeiras pode desempenhar, denominados como "substitutos" (surrogate mother), desenvolvem a personalidade do paciente a partir da reativação de suas experiências anteriores, papéis esses que encontram resistência por parte de algumas delas.
Após uma abordagem geral da teoria e, especificamente, do seu processo, resta-nos tecer algumas reflexões acerca de sua utilidade para a prática profissional.

Analisar uma teoria de acordo com o critério da utilidade requer verificar se a teoria é proveitosa para a prática da enfermagem, ao ensino e à pesquisa $^{(3)}$. Do ponto de vista prático, a teoria poderia fornecer à enfermeira uma estrutura de referência para auxiliá-la a tomar decisões quanto ao cuidado com os pacientes. Quanto ao ensino, a teoria poderia oferecer as bases para a organização do currículo, indicando métodos adequados. No âmbito da pesquisa a teoria tem utilidade para a enfermeira pesquisadora à medida que sugere importantes problemas e métodos apropriados para investigação.

Barnum indica que se uma teoria for tão obscura a ponto de não poder ser aplicável às operações e decisões do dia-a-dia, ela é falha no que se refere ao critério de utilidade ${ }^{(3)}$. A autora reconhece, entretanto, que as pessoas podem discordar quanto ao que seja ou não utilizável. Mesmo assim, para que a teoria possa ser utilizável, sugere que é preciso que os conceitos que ela apresenta tenham correspondência com o mundo das atividades de enfermagem e, por sua vez, que sejam operacionalizáveis ${ }^{(3)}$.

Após uma leitura atentiva da Teoria das Relações Interpessoais ${ }^{(7)}$, de trabalhos apresentados posteriormente ao desenvolvimento da teoria por Peplau ${ }^{(9)}$, bem como da análise de estudos desenvolvidos utilizando-a como marco teórico, compreendemos que a teoria de Hildegard Peplau, mesmo tendo sido apresentada há cinco décadas e sob outro contexto histórico, continua atual, pois seu foco central, a saber, a relação interpessoal enfermeiro-paciente faz parte da própria natureza da enfermagem e, continuamente, a visão holística apresentada pela autora - na qual as experiências, expectativas, valores e crenças do indivíduo devem ser valorizadas ${ }^{(13-14)}$ - tem sido resgatada como uma forma de produzir uma enfermagem humanitária, em um momento em que continuamente a enfermagem se ressente da necessidade de uma maior interação com os pacientes.

Em nossa análise, os conceitos e as fases do processo por ela apresentadas na teoria de Peplau são claras e operacionalizáveis. Percebemos durante a leitura dos escritos da teórica que, a todo momento ela procura resgatar exemplos do cotidiano da enfermagem para evidenciar como as etapas podem ser desenvolvidas na prática, $\mathrm{o}$ que torna mais clara sua aplicação. 
Consideramos que, embora a teoria tenha sido relacionada à prática da enfermagem psiquiátrica, ela pode ser utilizada em quaisquer situações em que a enfermeira possa estabelecer algum tipo de interação com o paciente. Isso se tornou evidente para nós pelos trabalhos que têm sido desenvolvidos a partir do referencial teórico de Hildegard Peplau ${ }^{(15-17)}$.

Baseando-nos no critério de utilidade de Barnum, entendemos que a Teoria das Relações Interpessoais pode ser útil não somente para a prática, conforme argumentamos anteriormente, mas também para o ensino de enfermagem - inclusive servindo de base para avaliação de alunos. A própria autora defende a idéia de que o relacionamento interpessoal deve ser iniciado ainda na formação dos alunos, pois preconiza que a forma como os docentes se relacionam com os estudantes de enfermagem se reflete na maneira como esses alunos interagirão com os pacientes ${ }^{(7)}$.

Em relação ao uso da teoria no campo da pesquisa, no nosso entender a descrição do processo de atuação da enfermagem poderia fornecer um direcionamento acerca da forma de investigar determinado problema científico. As etapas previstas para a interação enfermeira-paciente poderiam ser reproduzidas na interação entre pesquisador e sujeito de pesquisa ${ }^{(15)}$.

\section{CONSIDERAÇÕES FINAIS}

Com base nas considerações elaboradas nesse estudo pudemos verificar a importância das teorias de enfermagem para a prática profissional, dentre as quais destacamos a Teoria das Relações Interpessoais.

Percebemos que o arcabouço teórico apresentado pela autora reflete sua preocupação com a compreensão da natureza da enfermagem presente à época do desenvolvimento da teoria. Nesse sentido, foi possível identificar que a enfermagem é vista, sobretudo, como uma forma de interagir com o paciente e, por meio desta relação, fazer do adoecer uma oportunidade para o crescimento e o amadurecimento pessoal de ambos.

Para este fim, a autora enfoca as fases de orientação, identificação, exploração e resolução, na qual a enfermeira desenvolve diferentes papéis para auxiliar o paciente no desenvolvimento de suas necessidades, até que esse esteja pronto a assumir uma atuação independente da enfermeira.

Quanto à utilidade da teoria entendemos que, de fato vale a pena continuar investindo nos pressupostos teóricos da autora, pois estes, em última análise, resgatam o sentido humano na atuação da enfermagem. Os pressupostos teóricos são operacionalizáveis na prática, no ensino e na pesquisa de enfermagem e, apesar de terem sido desenvolvidos em meados do século XX, podem servir como base para atuação dos enfermeiros do século XXI, não só no âmbito da Enfermagem Psiquiátrica, mas em quaisquer situações onde estes possam comunicar-se, interagir com seus pacientes.

Reconhecemos que o êxito nessa tarefa é dificultado, em muitas das vezes, pela ausência de condições favoráveis nos serviços de saúde no sentido de proporcionar uma interação significativa, tanto do ponto de vista quantitativo quanto qualitativo, entre enfermeiro e paciente. Entretanto, vislumbramos a necessidade de um esforço por parte dos enfermeiros para que, de fato, as idéias expostas pela autora possam ser utilizadas como referência para a prática, contribuindo para um cuidado no qual os enfermeiros possam reconhecer a si e ao ser cuidado como pessoas em interação e co-participantes nesse processo.

É possível que, na opinião de alguns enfermeiros, os pressupostos da teórica talvez não sejam adequados à realidade prática, o que, de alguma forma, tem sua razão de ser, tendo em vista o modelo biomédico que determinou e ainda determina a formação e a assistência dos profissionais da área de saúde, dificultando visualizar a pessoa que recebe atendimento para além de sua doença.

Ademais, a prática da enfermagem sempre esteve pautada nas técnicas e, quando ouvimos falar de uma teoria que ressalta a interação pessoa-pessoa isso pode não parecer algo tão facilmente operacionalizável. De certo modo, poderíamos até nos questionar em que medida nós enfermeiros temos conseguido estabelecer uma interação com nossos pacientes quando essa não está mediada por técnicas.

Nesse sentido, chamamos a atenção de que, para um relacionamento interpessoal satisfatório, faz-se necessário que os enfermeiros estejam atentos às suas próprias necessidades e desenvolvam um processo de auto-conhecimento, pois é difícil interagir com o outro sem sermos capazes de compreendermos a nós mesmos.

Entendemos, adicionalmente, que o primeiro passo para aplicar uma teoria é conhecê-la e, dessa forma, acreditamos que este trabalho possa trazer uma contribuição significativa, fomentando o interesse pela Teoria das Relações Interpessoais, uma vez que estudos recentes enfocando essa te-
Teoria das Relações Interpessoais de

Peplau: análise fundamentada em Barnum 
Vitória de Cássia F. Almeida Marcos V. de O. Lopes Marta Maria C. Damasceno oria são escassos, o que pode estar relacionado com o fato de ter sido desenvolvido no contexto específico da Psiquiatria. Portanto, sugerimos que outros estudos possam ser realizados para avaliar, em diferentes situações de cuidado, a uti- lidade, não apenas dos pressupostos dessa autora, mas também os de outras teóricas de Enfermagem. Somente por esse caminho conseguiremos desmis-tificar o uso de teorias de Enfermagem como algo fora de nossa realidade.

\section{REFERÊNCIAS}

(1) Westphalen MEA, Carraro TE, organizadoras. Metodologias para a assistência de enfermagem: teorizações, modelos e subsídios para a prática. Goiânia: AB; 2001.

(2) Riehl JP, Roy C. Conceptual models for nursing practice. $2^{\text {nd }}$ ed. New York: Appleton-CenturyCrofts; 1980.

(3) Barnum BS. Nursing theory: analysis, application, evaluation. $5^{\text {th }}$ ed. Philadelphia: Lippincott; 1998.

(4) Leopardi MT. Teorias de enfermagem: instrumentos para a prática. Florianópolis: Papa-Livros; 1999.

(5) Hickman JS. Introdução à teoria da enfermagem. In: George JB, editor. Teorias de enfermagem: os fundamentos para a prática profissional. $4^{\mathrm{a}} \mathrm{ed}$. Porto Alegre: Artes Médicas Sul; 2000. p. 11-20.

(6) Chinn PL, Krammer MK. Theory and nursing: a systematic approach. $4^{\text {th }}$ ed. Saint. Louis: Mosby; 1995.

(7) Peplau HE. Relaciones interpersonales en enfermería: um marco de referência conceptual para la enfermería psicodinámica. Barcelona: MassonSalvat; 1990.

(8) Sills G. Hildegard E. Peplau: académica, educadora y líder de la enfermería. Trad. de Liria Pérez Peláez. Invest Educ Enferm [periodico online] 1999; 17(2). Disponíble en: http://tone.udea.edu.co/revista/ sep99/homenajeesp.htm (25 ago. 2003)

(9) O'Toole AW, Welt SR. Teoría interpersonal en la práctica de la enfermería: trabajos seleccionados de Hildegard E. Peplau. Barcelona: Masson; 1996.
(10) George JB. editor. Teorias de enfermagem: os fundamentos para a prática profissional. $4^{\mathrm{a}}$ ed. Porto Alegre: Artes Médicas Sul; 2000.

(11) Martí GN. Prólogo a la edición española. In: Peplau HE. Relaciones interpersonales en enfermería: um marco de referência conceptual para la enfermería psicodinámica. Barcelona: Masson-Salvat; 1990.

(12) Leddy S, Pepper JM. Bases conceptuales de la enfermería profesional. Washington: Organización Panamericana de La Salud; 1989. La teoría como base de la práctica; p. 135-58.

(13) Hoga LAK. A dimensão subjetiva do profissional na humanização da assistência à saúde: uma reflexão. Rev Esc Enferm USP 2004; 38(1):13-20.

(14) Neto DL, Nóbrega MML. Holismo nos modelos teóricos de enfermagem. Rev Bras Enferm 1999; 52(2):233-42.

(15) Pinheiro AKB. Depois do parto tudo muda: um novo olhar sobre adolescentes nutrizes. [tese] Fortaleza (CE): Universidade Federal do Ceará; 2003.

(16) Ataíde MB, Pagliuca LM, Damasceno MM. Interrelação dos propósitos da teoria de Peplau com o cuidado ao diabético. Rev Bras Enferm 2002; 55(6):674-9.

(17) Santos SSC, Henriques MERM. Idosos hospitalizados a partir dos pressupostos da Teoria de Peplau. Rev RENE 2000; 1(2):77-82.
Correspondência:

Vitória de C. F. de Almeida Av. Mozart Lucena, 2150 Jd. Guanabara

Fortaleza

CEP - 60347-440 - CE

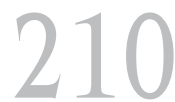

Rev Esc Enferm USP 2005; 39(2):202-10. 